\title{
Platynosomum illiciens (TREMATODA: DICROCOELIDAE) EM SAGUI (Callithrix spp.) NO MUNICÍPIO DE SEROPÉDICA, RJ - RELATO DE CASO
}

\author{
(Platynosomum illiciens (trematoda: dicrocoelidae) in marmoset (Callithrix spp.) in the municipality of \\ Seropédica, RJ - case report)
}

Rayane Christine Pereira de Assis, Debora Azevedo Borges, Carlos Alexandre Rey Matias, Julia Aline Santos de Mello, Carlos Wilson Gomes Lopes, Diefrey Ribeiro Campos, Barbara Rauta de Avelar, Fabio Barbour Scott

Universidade Federal Rural do Rio de Janeiro - UFRRJ, Rio de Janeiro, Brasil.

*Correspondência: rayanecpassis@gmail.com

RESUMO: A espécie Platynosomum illiciens é um trematódeo do trato biliar, principalmente de felídeos, tendo sido relatado também em aves e outras espécies de mamíferos como em primatas não humanos. Portadores de uma ampla variação morfológica, o gênero Platynosomum é discutido por diversos autores quanto as suas características morfológicas. A manifestação clínica da doença é denominada platinosomíase e nos primatas a maioria dos relatos são post mortem. Os sinais clínicos e patogenia não estão totalmente elucidados. Pode-se observar má condição corporal, queda de pelos, anorexia, diarreia, vômitos, hepatomegalia, icterícia e desidratação que podem levar $\mathrm{O}$ animal a óbito. $\mathrm{O}$ objetivo deste estudo foi identificar e relatar o parasitismo por $P$. illiciens em um primata não humano, fêmea, adulta do gênero Callithrix que vivia em um Centro de Triagem de Animais Silvestres no município de Seropédica RJ. O diagnóstico foi através de técnicas coproparasitológicas, avaliação morfológica de espécimes adultos recuperados através de necrópsia e análise molecular. A avaliação da amostra fecal foi realizada com as técnicas coproparasitológicas centrífugo-flutuação simples com solução de sacarose e sedimentação em formalina-éter. Onde, foram encontrados ovos de coloraçao marrom, ovalados, operculados e com um miracidio em seu interior. A análise morfológica dos ovos indicou as dimensões dos diâmetros maior e menor, respectivamente, como $41,24 \mu \mathrm{m}(32,62-46,76)$ e $28,13 \mu \mathrm{m}(22,05-37,67)$, com média de $1,79 \mu \mathrm{m}$ de espessura de parede. A análise morfológica dos espécimes adultos foi feita após o animal vir a óbito naturalmente. O animal, não possuía sinais clínicos sugestivos de platinosomíase. A mensuração foi feita a partir das medidas de comprimento e largura, respectivamente, do corpo $(6013-1367 \mu \mathrm{m})$, ventosa oral $(418-409 \mu \mathrm{m})$, faringe $(107-127 \mu \mathrm{m})$, acetábulo $(403-418 \mu \mathrm{m})$, testículo direito $(846-470 \mu \mathrm{m})$, testículo esquerdo $(910-515 \mu \mathrm{m})$, ovário (385-281 $\mu \mathrm{m})$ e bolsa do cirro $(500-145 \mu \mathrm{m})$. A detecção de DNA do trematódeo foi realizada por meio da reação em cadeia da polimerase (PCR). As sequências obtidas foram analisadas e comparadas aos isolados disponíveis na base de dados da plataforma GenBank. A análise filogenética indicou que as sequências dos fragmentos de rDNA 18S-ITS1-5.8S amplificadas a partir do trematódeo em questão, mostraram $100 \%$ de similaridades nucleotídicas com as sequências do GenBank KU987674 e MH156567 depositadas como derivadas de $P$. fastosum e $P$. illiciens recuperadas de fígado de gatos no Vietnã e nos Estados Unidos, respectivamente, concluindo que a espécie analisada se trata do $P$. illiciens.

Palavras-chaves: diagnóstico molecular; diagnóstico morfológico; diagnóstico parasitológico; primatas não humanos; trematoda.

\section{Agradecimentos}

Este estudo foi apoiado pela Fundação de Apoio à Pesquisa Tecnológica (FAPUR) da Universidade Federal Rural do Rio de Janeiro, Coordenação de Aperfeiçoamento Pessoal de Nível Superior, CAPES), Conselho Nacional de Desenvolvimento Científico e Tecnológico (CNPq) e Ministério da Educação (MEC).

\section{Nota}

Estudo realizado com a licença ICMBio/n57694-1. 